\title{
Clinical Characteristics of Colorectal Cancer Patients With a Second Primary Cancer
}

\author{
Jin Woo Lee, Jong Woo Kim, Nam Keun Kim ${ }^{1}$ \\ Department of Surgery, CHA University College of Medicine, Seongnam; ${ }^{1}$ Institute for Clinical Research, CHA University College of \\ Medicine, Seongnam, Korea
}

Purpose: The incidence of colorectal cancer is increasing due to a westernized dietary lifestyle, and improvements in treatment and diagnostic tools have resulted in more patients being confirmed of having multiple primary cancers. However, studies regarding multiple primary cancers are insufficient. In this study, the clinical aspects of patients with primary multiple cancers, including colorectal cancers, were investigated, and the results were compared to those of patients with primary colorectal cancer only.

Methods: Seven hundred eighteen patients who received surgery for colorectal cancer between March 2003 and September 2012 in CHA Medical Center were enrolled. A retrograde cohort was done for comparison of the two groups: those with and those without multiple primary cancer. The analysis was done according to sex, age, tumor location, tumor size, metastatic regional lymph-node number, vascular/lymphatic microinvasion, staging, tumor markers, microsatellite instability, and C/T subgroup of polymorphism in methylenetetrahydrofolate reductase.

Results: Of the 718 subjects, 33 (4.6\%) had multiple primary cancers: 12 (36.4\%) synchronous and 21 (63.6\%) metachronous. The malignancy most frequently accompanying colorectal cancer was gastric cancer, followed by thyroid, prostate, and esophageal malignancies in that order. In the comparison between groups, mean age, tumor location, and microsatellite instability showed statistically significant differences; others parameters did not.

Conclusion: The incidence of multiple primary cancers, including colorectal cancer, is increasing. Therefore, defining the characteristics of patients with multiple primary cancers is crucial, and those characteristics need to be acknowledged in the follow-up of colorectal cancer patients.

Keywords: Colorectal neoplasms; Multiple primary cancer

\section{INTRODUCTION}

Multiple primary malignant tumors can be defined as more than two different tumors synchronously or metachronously forming in the same organ or different organs. Coincident with the increasing interest in cancer and with advances in both radical treatments

Received: July 29, 2013 - Accepted: October 27, 2013

Correspondence to: Jong Woo Kim, M.D.

Department of Surgery, CHA Bundang Medical Center, CHA University,

59 Yatap-ro, Bundang-gu, Seongnam 463-712, Korea

Tel: +82-31-780-5250, Fax: +82-31-780-5259

E-mail: kjw@cha.ac.kr

(C) 2014 The Korean Society of Coloproctology

This is an open-access article distributed under the terms of the Creative Commons Attribution NonCommercial License (http://creativecommons.org/licenses/by-nc/3.0) which permits unrestricted non-

commercial use, distribution, and reproduction in any medium, provided the original work is properly cited. of malignant tumors and diagnosis techniques, the trend has been towards increasing frequency of multiple malignant tumors. Also, the recent westernization of diet has been driving a fast growth in the number of colorectal cancer patients in Korea, and the number of patients with multiple primary malignant tumors accompanying colorectal cancers has also been rising [1]. According to a number of reports, multiple primary malignant tumors accompanied by colorectal cancers have been found in about $2 \%-5 \%$ of all patients, and some findings have indicated that the newly occurring cancers are related to the prognosis of the previous cancer [24]. Therefore, quick diagnosis and treatment of secondary cancers are essential to the prognosis of patients. Lately in Korea, some research has been done on multiple primary malignant tumors and on those accompanying colorectal cancers intermittently; however, the number of such patients is not sufficient $[5,6]$. In this study, we present the clinical characteristics of patients with multi- 
ple primary malignant tumors accompanying colorectal cancers and the differences between those characteristics and those of patients with primary colorectal cancer.

\section{METHODS}

We divided 718 patients who had surgery at one hospital from March 2003 until September 2012 into a group of patients with multiple primary malignant tumors and a group of patients with primary colorectal cancer, and we conducted a retrospective study based on their medical history and test results in order to do a comparative analysis. The investigation addressed sex, age, tumor location, tumor size, number of metastatic regional lymph nodes if any, microvessel/lymphatic invasion, clinical stage, tumor marker, microsatellite instability (MSI) and lastly, C/T, the typical genetic morphism of methylenetetrahydrofolate reductase (MTHFR), which is involved in DNA methylation. The tumor location was classified into the right colon from the ascending colon to the transverse colon and the left colon from the descending colon to the transverse colon. These clinical factors were investigated to determine if any of them were linked to the formation of multiple primary cancers. The software package IBM SPSS ver. 19.0 (IBM Co., Armonk, NY, USA) was utilized for the statistical analysis, and P-values of less than 0.05 were interpreted as statistically significant.

\section{RESULTS}

Of a total of 718 patients with diagnosed colorectal cancer, 33 (4.6\%) developed multiple primary malignant tumors in other organs. Among the 33 patients, $7(21.2 \%)$ had had a previous cancer in an organ other than the colon; 26 cases $(78.8 \%)$ had had a colorectal cancer previously. Of those 33 patients, 12 (36.4\%) had synchronous tumors with the interval between the first and the second cancers being shorter than 6 months while 21 (63.6\%) had metachronous tumors with the interval between the first and the second cancers being longer than 6 months (average interval, 4.3 years). Two of the 33 patients had multiple primary malignant tumors in more than 3 parts of their organs (Table 1).

The malignant tumors accompanying colorectal cancer most frequently were stomach cancer, (12 patients, 36.4\%), followed by thyroid cancer (5 patients, $15.1 \%$ ), prostate cancer (5 patients,

Table 1. Proportion of multiple primary cancers and synchronicity

\begin{tabular}{lc}
\hline Variable & No. of patients (\%) \\
\hline Total & $718(100)$ \\
Single colon cancer & $685(96.6)$ \\
Multiple primary cancer & $33(3.4)$ \\
Synchronous & $12(36.4)$ \\
Metachronous & $21(63.6)$ \\
\hline
\end{tabular}

$15.1 \%)$, and esophageal cancer (2 patients, $6 \%$ ). Other sites of primary cancers were the liver, common bile duct, pancreas, small intestine, lung, bladder, ureter, kidney, uterus, cervix (one incidence each, 30.3\%) (Table 2).

When the differences between the patients with multiple primary cancers and those with single colorectal cancer were assessed, the average age was $67.15 \pm 11.7$ years for multiple-primary-cancer group and $62.44 \pm 12.3$ years for the single-colorectal-cancer group, and that difference was statistically significant $(\mathrm{P}$ $=0.032$ ). The multiple-primary-cancer group included 24 males (72.7\%) and 9 females (27.3\%) while the single-colorectal-cancer group included 400 males (58.4\%) and 285 females (41.6\%). The ratio of males to females was much higher in multiple-primarycancer group, but this difference was not statistically significant.

The tumor size, number of metastasized regional lymph nodes, and microvessel/lymphatic invasions were not different between the two groups. In terms of tumor location, $16(48.5 \%)$ were located in the right colon cancer was and $17(51.5 \%)$ were located in the left colon for the multiple-primary-cancer group (33 patients) while $202(29.5 \%)$ were located in the right colon and $483(70.5 \%)$ were located in the left colon for the single-colon-cancer group (685 patients), showing a higher number of tumors in the right colon for the multiple-primary-cancer group, which was statistically significant $(\mathrm{P}=0.02$; odd ratio $[\mathrm{OR}], 2.25)$.

Clinical staging was divided into four stages from 1 to 4 , but distinctions among the stages showed no statistical significance. Categorizing stages 1 and 2 as early colorectal cancer and stages 3 and 4 as progressive colorectal cancer did not show any statistical dis-

Table 2. Distribution of second primary cancers

\begin{tabular}{|c|c|c|c|c|}
\hline Site & Sex & $\begin{array}{c}\text { No. of } \\
\text { patients (\%) }\end{array}$ & Synchronicity & $\begin{array}{c}\text { Interval of } \\
\text { diagnosis (mo) }\end{array}$ \\
\hline \multirow[t]{3}{*}{ Stomach } & Total & $12(36.4)$ & & 49 \\
\hline & Male & 11 & Synchronous: 4 & \\
\hline & Female & 1 & Metachronous: 8 & \\
\hline \multirow[t]{3}{*}{ Thyroid } & Total & $5(15.1)$ & & 44 \\
\hline & Male & 1 & Synchronous: 1 & \\
\hline & Female & 4 & Metachronous: 4 & \\
\hline \multirow[t]{3}{*}{ Prostate } & Total & $5(15.1)$ & & 64 \\
\hline & Male & 5 & Synchronous: 3 & \\
\hline & Female & 0 & Metachronous: 2 & \\
\hline \multirow[t]{3}{*}{ Esophagus } & Total & $2(6.0)$ & & 8 \\
\hline & Male & 2 & Synchronous: 0 & \\
\hline & Female & 0 & Metachronous: 2 & \\
\hline \multirow[t]{3}{*}{ Other ${ }^{\mathrm{a}}$} & Total & 10 (30.3) & & 55 \\
\hline & Male & 6 & Synchronous: 4 & \\
\hline & Female & 4 & Metachronous: 6 & \\
\hline
\end{tabular}

${ }^{a}$ One patient each with cancer of the liver, common bile duct, pancreas, small bowel, lung, bladder, ureter, kidney, uterus, and cervix. 
tinctions.

Tumor markers showed no statistical differences between the multiple primary cancer group and the single colon cancer group. MTHFR was classified into two groups: the CC/CT group of the wild type and the heterogeneous type, and the TT group of the mutant type, but the groups showed no statistically significant differences. For MSI, five microsatellite markers were analyzed. Cases in which instability was found in more than two markers were defined as MSI-high cases whereas cases in which instability was found in zero or one marker were defined as microsatellite

Table 3. Patients' characteristics

\begin{tabular}{|c|c|c|c|c|}
\hline Characteristic & $\begin{array}{l}\text { Multiple primary } \\
\text { cancers (\%) }\end{array}$ & $\begin{array}{l}\text { Single colon } \\
\text { cancer (\%) }\end{array}$ & P-value & Odds ratio \\
\hline Age (yr) & $67.15 \pm 11.7$ & $62.44 \pm 12.3$ & 0.032 & \\
\hline Sex & & & 0.102 & 1.90 \\
\hline Male & $24(72.7)$ & $400(58.4)$ & & \\
\hline Female & $9(27.3)$ & $285(41.6)$ & & \\
\hline Location & & & 0.020 & 2.25 \\
\hline Right & $16(48.5)$ & 202 (29.5) & & \\
\hline Left & 17 (51.5) & $483(70.5)$ & & \\
\hline Tumor size (cm) & $4.95 \pm 2.4$ & $5.3 \pm 2.4$ & 0.47 & \\
\hline LN number & $1.24 \pm 3.8$ & $2.6 \pm 6.2$ & 0.205 & \\
\hline LV invasion & & & 0.785 & 1.10 \\
\hline No invasion & $18(54.5)$ & $357(52.1)$ & & \\
\hline Invasion & $15(45.5)$ & $328(47.9)$ & & \\
\hline Stage & & & 0.065 & \\
\hline Early 1 & $7(21.2)$ & 90 (13.2) & & \\
\hline Early 2 & 17 (51.8) & $263(38.6)$ & & \\
\hline Advanced 3 & $9(27.3)$ & $258(37.8)$ & & \\
\hline Advanced 4 & $0(0)$ & $71(10.4)$ & & \\
\hline CEA & & & 0.333 & 1.52 \\
\hline Normal & $24(77.4)$ & $466(69.2)$ & & \\
\hline Abnormal & $7(22.6)$ & $207(30.8)$ & & \\
\hline CA 19-9 & & & 0.766 & 0.84 \\
\hline Normal & $22(84.6)$ & $526(86.8)$ & & \\
\hline Abnormal & $4(15.4)$ & 80 (13.2) & & \\
\hline MTHFR & & & 0.936 & 1.04 \\
\hline TT & $5(15.6)$ & $98(15.1)$ & & \\
\hline CC/CT & $27(84.4)$ & $551(84.9)$ & & \\
\hline $\mathrm{MSI}$ & & & 0.001 & 3.51 \\
\hline Low & $9(27.3)$ & $619(90.4)$ & & \\
\hline High & 24 (72.7) & $66(9.6)$ & & \\
\hline
\end{tabular}

Values are presented as mean \pm standard deviation or number (\%).

LN, lymph node; CEA, carcinoembryonic antigen; CA 19-9, carbohydrate antigen 19-9; MTHFR, methylenetetrahydrofolate reductase; MSI, microsatellite instability. stability (MSS)/MSI-low cases. While the multiple-primary-cancer group included $24 \mathrm{MSI}$-high patients (72.7\%) and $9 \mathrm{MSS} /$ MSI-low patients (27.3\%), the multiple-primary-cancer group had 66 MSI-high patients (9.6\%) and 619 MSS/MSI-low patients $(90.4 \%)$, a statistically significant difference $(\mathrm{P}=0.001)$ (Table 3$)$.

\section{DISCUSSION}

Multiple primary malignant tumors were first reported by Billroth [7] in 1889, but his criteria were somewhat complicated; hence, the definition published in 1932 by Warren and Gates [8] has been widely used. The diagnostic criteria of multiple primary cancers are as follows: firstly, each tumor should be histopathologically malignant; secondly, each tumor should be histologically different; thirdly, the possibility of metastasis of each tumor should be ruled out. Later on, Moertel [9] categorized multiple primary cancers into three groups: tumors formed in the same organ, tumors formed in different organs, and the combination of the first two cases. This study took only the second group into account.

The criterion for a tumor's being "synchronous" or "metachronous" is 6 months or 1 year depending on the study, but this research adopted 6 months as a standard $[10,11]$. The study conducted by Kim et al. [12] reported that $36.3 \%$ chance of a tumor's being synchronous and $63.7 \%$ chance of its being metachronous and those results are quite similar to the results of our research. Moreover, in the case of metachronous tumors, the occurrence interval was reported to be 4.16 years by Kim et al. [12], and 5.7 years by Yoon and Kim [13]. In this study, the occurrence interval for metachronous cancer patients was 4.3 year on average.

Kim et al. [12] revealed the number of cases in which the second cancer was diagnosed due to symptoms was larger than the number of cases in which the second cancer was diagnosed from a follow-up test. In addition, by the time patients started to perceive the symptoms, they were more likely already to have progressive cancer; thus, detailed attention when conducting follow-up observations is necessary if cancers that have developed in other parts of the body are to be found. During this study, we discovered that many patients who had a first colorectal cancer also developed stomach cancer, thyroid cancer, and prostate cancer; therefore, we insist that follow-up observation after surgery for colorectal cancer has to include gastroscopy, thyroid ultrasonography, abdominal ultrasonic examination, etc.

In Korea, the most-frequently diagnosed cancers that are affected by major malignant tumors are stomach cancer $(21.6 \%)$, liver cancer (11.5\%), lung cancer (11.2\%), cervical cancer $(9.4 \%)$, colorectal cancer $(8.2 \%)$, female breast cancer (5.3\%), hematopoietic cancer $(3.0 \%)$, thyroid cancer $(2.8 \%)$, and bladder cancer $(2.2 \%)$, and the frequency of multiple primary cancer is high for the stomach and the colon $[14,15]$. On the other hand, the most common sites for cancers in Western countries are the female breast, large intestine and prostate gland probably because the rate of stomach cancer is low $[16,17]$. 
In this study, there was no meaningful difference in the average age between the multiple-primary-cancer group, 67.15 years, and the single-colon-cancer group, 62.44 years. This is similar to the result of Kim et al. [12]'s study.

MTHFR is an enzyme that takes part in acid metabolism, catalyzes the conversion of 5,10-methylenetetrahydrofolate to 5-methyltetrahydrofolate, a cosubstrate for homocysteine remethylation to methionine, and plays a major role in DNA methylation [18, 19]. Many past studies found that genetic variation of MTHFR might influence the susceptibility to colon cancer, and it was found to affect other cancers such as breast cancer, ovarian cancer, etc. $[20,21]$. Even though this study concluded that genetic mutation of MTFHR had nothing to do with multiple primary cancers, judging from the fact that disorders of folic acid metabolism and DNA methylation are associated with the incidence of various cancers, additional studies on this matter are necessary.

Multiple primary malignant tumors have been mentioned to be attributable to iatrogenic, environmental and hereditary factors, but such associations are only partially understood. Cheng et al. [22] reported that approximately $40 \%$ of patients with metachronous multiple primary malignant tumors had a history of receiving anticancer treatments or radiation therapy in an attempt to cure the symptoms of their first cancer, but developed secondary tumors within 3-8 years following their initial treatment. In other words, anticancer treatments and radiation therapy were the major causes of multiple primary malignant tumors. Common environmental factors that contribute to cancer death include smoking tobacco and drinking alcohol, and especially when multiple tumors develop in the respiratory and the digestive systems, these environmental factors need to be considered [23].

Hereditary factors may be another cause of multiple primary malignant tumors, as well. Hayashi et al. [24] carried out a study on a correlation between the loss of mismatch repair protein (MMR protein) and MSI among stomach-cancer and colorectalcancer patients with multiple primary malignant tumors. The study revealed that $23 \%$ of the colorectal cancer patients with accompanying stomach cancer showed MSI while $8 \%$ of primary colorectal cancer patients showed MSI. In addition, $12 \%$ of multiple stomach and colorectal cancer patients showed loss of MMR protein, which in all the identical MMR protein (hMLH1 or hMSH2). Furthermore, Hayashi et al. [24] suggested that MMR protein deficiency was closely related to a high incidence of right colon cancer and multiple colorectal cancers; thus, great care needs to be taken to look for stomach cancer during follow-up observation for those colorectal cancer patients with MMR protein deficiency. Taking it into account that $73 \%$ of multiple-primary-cancer patients and 9\% of single-colon-cancer cancer patients showed MSI and that right colon cancer came with more developed multiple primary cancers than left colon cancer in our study, we conclude that hereditary factors are highly likely to have played a role in the process.

This study was a retrospective research based on medical re- ports. Thus, some discrepancies in the method of follow-up observation and its duration for each patient might exist. Because the existence of such discrepancies could cause statistical errors, that is a potential limitation of this study.

In conclusion, due to the increasing number of colorectal cancer patients and to advances in cancer diagnosis and treatment, the number of patients with multiple malignant tumors accompanying colorectal cancer has been rising in recent years. Therefore, understanding the clinical characteristics of patients with multiple primary cancers better has become necessary, and more detailed attention needs to be paid to those characteristics during followup observations of those patients.

\section{CONFLICT OF INTEREST}

No potential conflict of interest relevant to this article was reported.

\section{REFERENCES}

1. Kim HC, Kim CN, Jung CS, Yu CS, Kim JC. Multiple primary malignant neoplasm with colorectal cancer. J Korean Cancer Assoc 1998;30:668-74.

2. Papadopoulos V, Michalopoulos A, Basdanis G, Papapolychroniadis K, Paramythiotis D, Fotiadis P, et al. Synchronous and metachronous colorectal carcinoma. Tech Coloproctol 2004;8 Suppl 1:S97-100.

3. Takeuchi H, Toda T, Nagasaki S, Kawano T, Minamisono Y, Maehara Y, et al. Synchronous multiple colorectal adenocarcinomas. J Surg Oncol 1997;64:304-7.

4. Ueno M, Muto T, Oya M, Ota H, Azekura K, Yamaguchi T. Multiple primary cancer: an experience at the Cancer Institute Hospital with special reference to colorectal cancer. Int J Clin Oncol 2003;8: $162-7$

5. Bae JM, Kim SW, Kim SW, Song SK. Metachronous four primary malignancies in gastro-intestinal tract. Korean J Gastroenterol 2009;53:373-7.

6. Cho WH, Kim JS, Lee SY, Kim BH, Lee SJ, Lee JH, et al. Synchronous double primary cancer: gastric hepatoid adenocarcinoma and rectal adenocarcinoma. Korean J Gastrointest Endosc 2005; 31:409-13.

7. Billroth T. Die allgemeinechirurgischepathologie und therapie in 51 Vorlesungen: einhandbuch fur Studirende und Arzte, 14 Aufl. Berlin, Germany: G. Reimer; 1889.

8. Warren S, Gates O. Multiple primary malignant tumors: A survey of the literature and a statistical study. Am J Cancer 1932;16:13581414.

9. Moertel CG. Multiple primary malignant neoplasms: historical perspectives. Cancer 1977;40(4 Suppl):1786-92.

10. FRIED BM. Primary multiple cancers. AMA Arch Surg 1958;77: 730-41.

11. Yamamoto S, Yoshimura K, Ri S, Fujita S, Akasu T, Moriya Y. The 
risk of multiple primary malignancies with colorectal carcinoma. Dis Colon Rectum 2006;49(10 Suppl):S30-6.

12. Kim SH, Kim HJ, Lee JI, Lee YS, Kang WK, Park JK, et al. Multiple primary cancers including colorectal cancer. J Korean Soc Coloproctol 2008;24:467-72.

13. Yoon HK, Kim JP. Multiple primary malignant neoplasm. J Korean Surg Soc 1984;26:1-9.

14. Korea Central Cancer Registry. 2002 Annual Report of the Korea Central Cancer registry, based-on registered data from 139 hospitals. Goyang: National Cancer Center; 2003.

15. Koo DJ, Yoon DS, Lee JJ, Park CJ. Clinical analysis of 65 multiple primary cancer cases. J Korean Surg Soc 1999;56:137-42.

16. Mariotto AB, Rowland JH, Ries LA, Scoppa S, Feuer EJ. Multiple cancer prevalence: a growing challenge in long-term survivorship. Cancer Epidemiol Biomarkers Prev 2007;16:566-71.

17. Evans HS, Moller H, Robinson D, Lewis CM, Bell CM, Hodgson SV. The risk of subsequent primary cancers after colorectal cancer in southeast England. Gut 2002;50:647-52.

18. Choi SW, Mason JB. Folate and carcinogenesis: an integrated scheme. J Nutr 2000;130:129-32.

19. Kuismanen SA, Holmberg MT, Salovaara R, Schweizer P, Aalton- en LA, de La Chapelle A, et al. Epigenetic phenotypes distinguish microsatellite-stable and -unstable colorectal cancers. Proc Natl Acad Sci USA 1999;96:12661-6.

20. Chen J, Giovannucci E, Kelsey K, Rimm EB, Stampfer MJ, Colditz $\mathrm{GA}$, et al. A methylenetetrahydrofolate reductase polymorphism and the risk of colorectal cancer. Cancer Res 1996;56:4862-4.

21. Gershoni-Baruch R, Dagan E, Israeli D, Kasinetz L, Kadouri E, Friedman E. Association of the C677T polymorphism in the MTHFR gene with breast and/or ovarian cancer risk in Jewish women. Eur J Cancer 2000;36:2313-6.

22. Cheng HY, Chu CH, Chang WH, Hsu TC, Lin SC, Liu CC, et al. Clinical analysis of multiple primary malignancies in the digestive system: a hospital-based study. World J Gastroenterol 2005; 11:4215-9.

23. Kiriu H, Yokozaki H, Yasui W, Ito K, Tahara E. Microsatellite instability associated with primary head and neck cancers and secondary esophageal cancers. Jpn J Clin Oncol 1998;28:733-9.

24. Hayashi T, Arai M, Ueno M, Kinoshita H, Tada Y, Koizumi K, et al. Frequency of immunohistochemical loss of mismatch repair protein in double primary cancers of the colorectum and stomach in Japan. Dis Colon Rectum 2006;49(10 Suppl):S23-9. 